FACULDADE DE CIÊNCIAS ECONÔMICAS DA UFRGS Análise
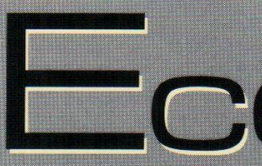

VALORES E PREÇOS DE PRODUÇÃO: UMA RELETURA de MARX Alfredo SAAD FILHO

OS ANTIGOS, OS NOVOS E OS NEO-INSTITUCIONALISTAS: HÁ CONVERGÉ NCIA TEÓ RICA NO PENSAMENTO INSTITUCIONALISTA

Octavio Augusto C. Conceição

A MENSURAÇÃ O DO GRAU DE INDEPENDÉNCIA DO BANCO CENTRAL: UMA ANÁLISE DE SUAS FRAGILIDADES HeLder Ferreira de MENDONÇA

A SUSTENTABILIDADE DA DÍVIDA MOBILIÁ RIA FEDERAL BRASILEIRA: UMA INVESTIGAÇĀ O ADICIONAL VIVIANE LUPORINI

O MODELO dE KRUGMAN EXPLICA A CRISE CAMBIAL. BRASILEIRA EM JANEIRO DE 1999?

Adriano CAMPOS MENEZES E TITO BELCHIOR S. MOREIR/

ESTRANGULAMENTO DA díVIDA EXTERNA E CRESCIMENTO ECONO MICO NA AMÉRICA LATINA: LIÇÓ ES DA DÉCADA DE 80

Marco Vaies buratto E SABino da SiLva P. JR.

CriaÇÃo e desvio de COMÉrCio: ANÁlise do FLuXo COMERCial ENTRE O Brasil. e O MERCOSUl para Alguns PRODUTOS INDUSTRIALIZADOS

Clá Udio Roberto fó fFano Vasconcelos

A EVOLUCÁ̃ DA INDÚ STRIA BRASILEIRA DE CELULOSE E SUA ATUAÇÃO NO MERCADO MUNDIAL

Emerson Martins HILGemberg e Carlos josé Caetano BACHA

A PROTEÇÃo SOCIAL NO PRIMEIRO QUARTEL DO SÉCULO XXI: BRINCANDO COM CENÁRIOS

rosa Maria Marques e Áquilas Mendes

ECONOMIA DO CRIME: ELEMENTOS TEÓ RICOS E EVIDÊNCIAS EMPÍRICAS

Gilberto José SChaefer e Pery Francisco Assis Shikida

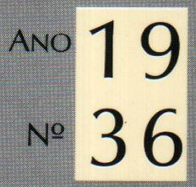


UNIVERSIDADE FEDERAL DO RIO GRANDE DO SUL

Reitora: Profa. Wrana Maria Panizzi

FACULDADE DE CIÊNCIAS ECONÔMICAS

Diretor: Prof. Pedro Cézar Dutra Fonseca

CENTRO DE ESTUDOS E PESQUISAS ECONÔMICAS

Diretor: Prof. Gentil Corazza

DEPARTAMENTO DE CIÊNCIAS ECONÔMICAS

Chefe: Prof. Luiz Alberto Oliveira Ribeiro de Miranda

DAPARTAMENTO DE CIÊNCIAS CONTÁBEIS E ATUARIAIS

Chefe: João Marcos Leão da Rocha

CURSO DE PÓS-GRADUAÇÃO EM ECONOMIA

Coordenador: Prof. Eduardo Pontual Ribeiro

CURSO DE PÓS-GRADUAÇÃO EM ECONOMIA RURAL

Coordenador: Prof. Jalcione Almeida

CONSELHO EDITORIAL: Achyles B. Costa, Aray M. Feldens, Carlos A. Crusius, Carlos G. A. Mielitz Netto, Eduardo A. Maldonado Filho, Eduardo P. Ribeiro, Eugênio Lagemann, Fernando Ferrari Filho, Gentil Corazza, Jan A. Kregel (Univ. of Bologna), Marcelo S. Portugal, Nali J. Souza, Otilia B. K. Carrion, Paulo A. Spohr, Paulo D. Waquil, Pedro C. D. Fonseca, Philip Arestis (Univ of East London), Roberto C. Moraes, Ronald Otto Hillbrecht, Stefano Florissi, Eleutério F. S. Prado (USP), Fernando H. Barbosa (FGV/RJ), Gustavo Franco (PUC/RJ), João R. Sanson (UFSC), Joaquim P. Andrade (UnB), Juan H. Moldau (USP), Paul Davidson (Univ. of Tennessee), Werner Baer (Univ. of Illinois).

COMISSÃO EDITORIAL: Eduardo Augusto Maldonado Filho, Fermando Ferrari Filho, Gentil Corazza, Marcelo Savino Portugal, Paulo Dabdab Waquil; Roberto Camps Moraes.

EDITOR: Fernando Ferrari Filho

EDITOR ADJUNTO: Pedro Silveira Bandeira

SECRETÁRIA: Vanessa Hoffmann de Quadros

REVISÃO DE TEXTOS: Vanete Ricacheski

FUNDADOR: Prof. Antônjo Carlos Santos Rosa

Os materiais publicados na revista Análise Econômica sāo da exclusiva responsabilidade dos autores. É permitida a reproduçāo total ou parcial dos trabalhos, desde que seja citada a fonte. Aceita-se permuta com revistas congêneres. Aceitam-se, também, livros para divulgação, elaboração de resenhas e recensões. Toda correspondência, material para publicação (vide normas na terceira capa), assinaturas e permutas devem ser dirigidos ao seguinte destinatário:

PROF. FERNANDO FERRARI FILHO

Revista Análise Econômica - Av. João Pessoa, 52 CEP 90040-000 PORTO ALEGRE - RS, BRASIL Telefones: (051) 316-3348 e 316-3440 - Fax: (051) 316-3990

E-mail: rae@vortex.ufrgs.br

Análise Econômica

Ano 18, n⿳3 33, março, 2000 - Porto Alegre

Faculdade de Ciências Econômicas, UFRGS, 2000

Periodicidade semestral, março e setembro.

1. Teoria Econômica - Desenvolvimento Regional -

Economia Agrícola - Pesquisa Teórica e Aplicada -

Periódicos. I. Brasil

Faculdade de Ciências Econômicas,

Universidade Federal do Rio Grande do Sul.

CDD 330.05

CDU 33 (81) (05) 


\title{
A sustentabilidade da dívida mobiliária federal brasileira: uma investigação adicional
}

Viviane Luporini*

\begin{abstract}
Resumo: Este artigo investiga a sustentabilidade da dívida mobiliária brasileira usando dados trimestrais de 1981 a 1998. Uma divida é considerada sustentável se a restrição orçamentária governamental é respeitada intertemporalmente. A sustentabilidade da dívida mobiliária federal é testada através da estacionaridade da razão divida/PIB ao redor da média zero, utilizando testes de raiz unitária tradicionais e testando a hipótese nula de estacionaridade. Confirmando diagnósticos previamente obtidos, os resultados indicam que a divida mobiliária federal assumiu um padrão insustentável durante o período estudado e que o governo tem, de fato, um incentivo para reestruturar sua dívida.
\end{abstract}

Palavras-chave: Dívida mobiliária federal; consolidação fiscal; Brasil.

\begin{abstract}
This paper further investigates the sustainability of the Brazilian Federal domestic debt using quarterly data from 1981 to 1998. A debt is considered sustainable if the government's budget is intertemporally balanced. Sustainability is tested through the mean-zero stationarity of the discounted debt/GDP ratio with standard unit root tests and the null hypothesis of stationarity. The results indicate that the federal domestic debt have assumed an unsustainable path during the period studied and that the government may indeed have an incentive to reestructure its debt.
\end{abstract}

Key words: Federal debt; fiscal result; Brazil.

\section{Introdução}

A experiência brasileira nos anos 80 e início dos anos 90 foi caracterizada por persistentes déficits orçamentários governamentais, crescimento econômico oscilante e altas taxas de inflação. Desde 1994, a estabilidade de preços foi alcançada e o governo tem feito um importante esforço para equilibrar seu orçamento. A dívida pública, particularmente do governo federal, atingiu, no entanto, níveis sem preceden-

- Universidade Federal de Minas Gerais - CEDEPLAR, apoio FAPEMIG.

Luporini@cedeplarufmg.br 
tes, alcançando 35,5\% do PIB brasileiro em novembro de 1998. De acordo com o Banco Central, esse desempenho é resultado principalmente de altas taxas internas de juros e da esterilização do fluxo de entrada de reservas internacionais. O plano de estabilização de preços implementado em 1994 era ancorado num regime de taxas fixas de câmbio. Um rígido controle da política monetária era então necessário para manter a taxa interna real de juros positiva e estimular a entrada de capital estrangeiro. A necessidade de se prevenir uma expansão da base monetária e o crescente gasto com pagamento de juros resultaram no aumento da razão dívida/PIB, observada desde 1995. Embora o valor da dívida mobiliária federal brasileira, em razão do PIB, não seja particularmente alto quando comparado com outros países, o padrão de seu crescimento leva à seguinte questão: estaria o governo brasileiro executando um jogo de Ponzi em que nova dívida é emitida a fim de fazer frente a sua própria rolagem e, portanto, a dívida mobiliária federal estaria assumindo um padrão insustentável?

Uma divida é considerada sustentável se a restrição orçamentária governamental é respeitada intertemporalmente e se sua dívida pode, conseqüentemente, ser liquidada por esperados superávits primários de igual valor presente (Hamilton 8 Flavin, 1986). Um governo não tem que manter seu orçamento balanceado todo o tempo para ter uma dívida sustentável, mas não pode ter déficits primários persistentes em seu orçamento (McCallum, 1984). A razão para isso é que indivíduos racionais não continuarão comprando títulos de um governo que não pretende pagar suas dívidas. Além disso, uma dívida mobiliária insustentável pode ameaçar a estabilidade de preços num cenário institucional onde a autoridade monetária não age independentemente e estabelece objetivos monetários de acordo com um orçamento fiscal preestabelecido.

Testes equivalentes aos apresentados aqui foram utilizados para dados anuais da dívida mobiliária federal brasileira no período 1966 a 1996 e os resultados indicaram que, embora a dívida mobiliária federal fosse sustentável até o final dos anos 70, ela assumiu um nível insustentável a partir de 1981 [Luporini, 1998]. Do ponto de vista econométrico, a dívida é sustentável se a série, apropriadamente descontada, é estacionária em torno da média zero. Algumas séries econômicas podem levar tempo, no entanto, para reverter às suas médias e o resultado previamente obtido de uma dívida federal insustentável para o período 1981-1996 pode ter sido obtido devido à pequena amostra utilizada.

O objetivo desse artigo é conduzir uma investigação adicional a res- 
peito do caminho não-sustentável assumido pela dívida mobiliária federal após 1981, utilizando observações trimestrais e estendendo a amostra até 1998. Essa nova amostragem permite um melhor entendimento da dinâmica da dívida mobiliária e fornece graus de liberdade suficientes para testar a sustentabilidade da dívida brasileira. Além dos testes tradicionais, esse artigo testa a sustentabilidade sob a hipótese nula de estacionaridade (Kwiatkowski, Phillips, Schmidt 8 Shin, 1992). Os testes de hipóteses são desenhados para rejeitar a hipótese nula a menos que haja forte evidência contrária. Testes tradicionais de raiz unitária têm a presença de raiz unitária (não-estacionaridade) como hipótese nula e falham em rejeitar a hipótese nula em diversas séries econômicas.

\section{A restrição orçamentária governamental}

Considerando a seguinte restrição orçamentária governamental nominal expressa em termos per capita no tempo t:

$B_{t}-B_{t-1}+M_{t}-M_{t-1}=P_{t} G_{t}-P_{t} T_{t}+i_{t-1} B_{t-1}$

onde:

$B_{t}-B_{t-1}$ é o montante em dólares da dívida do governo no período t;

$M_{t}-M_{t-1}$ é a variação do estoque monetário;

i é a taxa nominal de juros ex post, interpretada como o retorno sobre o estoque de dívida nas mãos do público';

$P_{t}$ é o nível de preços no tempo $\mathrm{t}$;

$\mathrm{G}$ e T são gastos e receitas governamentais, respectivamente.

O déficit real do governo pode ser definido como a variação, em termos reais, da divida governamental no tempo. A restrição orçamentária do governo deve ser ajustada pela inflação de modo que as mudanças em seus componentes não reflitam variações de preço. Além disso, é importante ajustar a restrição orçamentária às mudanças reais no nível de renda ou crescimento econômico.

A restrição orçamentária governamental em termos reais e como razão do PIB pode ser escrita:

$b_{t}-b_{t-1}+m_{t}-m_{t-1}=-s_{t}+\left(r_{t-1}-g_{t-1}\right) b_{t-1}-\left(\pi_{t-1}+g_{t-1}\right) m_{t-1}$

onde $s$ é o superávit primário sem juros (-s denota o déficit primário do governo, isto é, a diferença entre gastos realizados - excetuando-se pagamento de juros referentes à dívida federal - e receitas).

${ }^{1}$ Note que não é necessário assumir que o governo emite apenas títulos de um periodo. 
$r \equiv i-\pi$ representa a taxa real de juros e g denota a taxa de crescimento da renda.

Rescrevendo (2) para obter:

$b_{t}-b_{t-1}=-\vec{s}_{t}+\left(r_{t-1}-g_{t-1}\right) b_{t-1}$

onde $-\bar{s}_{t}=-s_{t}-\left(m_{t}-m_{t-1}\right)-\left(\pi_{t-1}-g_{t-1}\right) m_{t-1}$ é o negativo do superávit primário inclusive de receitas de seignoriagem ${ }^{2}$.

Seja $\alpha_{t} \equiv\left(r_{t}-g_{t}\right)$ e rescrevendo a equação (2') para obter:

$b_{t}=-\bar{s}_{t}+\left(1+\alpha_{t-1}\right) b_{t-1}$

Defina $Q_{t}=\prod_{j=0}^{N-1}\left(1+\alpha_{j}\right)^{-1} ; Q_{0}=1$. Multiplicando-se a equação (3) por $Q_{\mathrm{t}}$ obtém-se:

$Q_{t} b_{t}=Q_{t-1} b_{t-1}-Q_{t} \bar{s}_{t}$

Rescrevendo (4), obtém-se uma versão da equação (3) descontada até o período zero:

$B_{t}=B_{t-1}-\bar{S}_{t}$

Substituindo (5) recursivamente para frente, obtém-se a restrição orçamentária intertemporal do governo, que agora envolve o valor de mercado da dívida do governo, no seu valor presente da data inicial:

$$
B_{t}=B_{t+N}+\sum_{j=1}^{N} \bar{S}_{t+j}
$$

A dívida é sustentável se a restrição orçamentária governamental é respeitada intertemporalmente. Nesse sentido, a questão relevante é o que os credores esperam que aconteça com $B_{t+N}$ na medida em que $\mathrm{N}$ varia.

${ }^{2}$ Imposto inflacionário é a perda de capital imposta aos detentores de encaixes reais $\left(\pi_{t} \cdot \frac{M_{t}}{P_{t}}\right)$ pela inflaçāo. A seignoriagem equivale ao imposto inflacionário adicionado da variaçāo real nos encaixes reais da economia, ou seja, $\left(\pi_{t} \cdot \frac{M_{t}}{P_{t}}\right)+\left(\frac{M_{t}}{P_{t}}-\frac{M_{t-1}}{P_{t-1}}\right)$.

A seignoriagem representa uma renda real obtida pelo governo através da utilização da emissāo de moeda para a aquisição de bens e ativos não-monetários. 
Aplicando a esperança matemática no tempo t em (6) e calculando-se o limite com $N$ tendendo ao infinito, tem-se a equação (7):

$$
B_{t}=\lim _{t \rightarrow \infty} E_{t} B_{t+N}+E_{t} \sum_{j=1}^{N} \bar{S}_{t+j}
$$

O orçamento do governo está balanceado em valor esperado presente, quando sua dívida pode ser liquidada pela soma descontada dos superávits esperados. De acordo com a equação (7), esse é o caso quando $\lim _{N \rightarrow \infty} B_{t+N}=0$. Se $\lim _{N \rightarrow \infty} B_{t+N}<0$, a soma descontada dos superávits esperados excede o valor presente da dívida do governo por um montante que não converge para zero. O governo está acumulando receitas que poderiam se traduzir em uma maior renda disponível para as famílias e conseqüente incremento do nível de consumo em todos os períodos. No caso oposto, $\lim _{N \rightarrow \infty} B_{t+N}>0$, o atual valor da dívida do governo excede o superávit primário esperado. Isso implica que o governo está continuamente tomando empréstimos para pagar juros de uma dívida que irá crescer, ceteris paribus, à taxa de juros e que os agentes econômicos estão provendo o governo de recursos a custo zero. Quando $\lim _{N \rightarrow \infty} B_{t+N}=0$, o governo está assintoticamente utilizando os recursos permitidos por sua restrição orçamentária, nada mais ou nada menos. É assumido que o montante de seignoriagem coletado pelo governo é consistente com uma taxa de inflação estável.

\section{Sustentabilidade da dívida mobiliária federal}

A amostra consiste de observações trimestrais de 1981:IV a 1998:III. A dívida do governo é a série "Dívida Mobiliária Interna Federal fora do Banco Central" publicada mensalmente pelo Banco Central do Brasil. Valores trimestrais consistem no estoque da dívida ao final de cada trimestre, valores de março, junho, setembro e dezembro.

Para calcular a taxa divida/PIB, valores trimestrais do PIB são necessários. Os valores correntes do Produto Interno Bruto medido trimestralmente não são, no entanto, publicados pelo IBGE (Instituto Brasileiro de Geografia e Estatística). Em seu Anuário Estatístico do Brasil, o IBGE publica um índice trimestral do PIB, o "Produto Interno Bruto Real Trimestral", que foi utilizado para se obter valores trimestrais do PIB. O índice foi escalado de forma que 1997: I = 1 e multiplicado pelo valor do PIB para o primeiro trimestre de 1997 (R $\$ 206.605$ milhões de 
1997, IPEA “Indicadores Conjunturais"), resultando numa série com valores trimestrais do PIB para preços constantes de 1997 (ver Tabela 1 em anexo).

A dívida nominal foi convertida em milhões de reais e dividida pelo índice geral de preços (IGP), demanda interna $(1997: 1=1)$. Seguindo a metodologia usada pelo IPEA, para evitar distorções resultantes de prazos diferenciados utilizados na coleta e publicação dos dados de dívida e PIB, a razão dívida/PIB para 1997:I, por exemplo, foi calculada da seguinte forma:

$\frac{D E B T_{1997 I}}{G D P_{1997 I}+G D P_{1996 I V}+G D P_{1996 I I I}+G D P_{1996 I I}}$.

A taxa real de juros seguiu a formulação $r=\frac{(1+i)}{(1+\pi)}-1$, onde $r$ é a taxa real de juros overnight para o trimestre (valores do mês compostos no trimestre) e $\pi$ é a taxa de inflação também acumulada no trimestre, isto é, $\pi_{1996: I}=\frac{I G P_{M a r 96}-I G P_{D e c} 95}{I G P_{D e c} 95}$. Essa definição de taxa real de juros é equivalente à definição padrão $r=i-\pi$ quando a taxa de inflação é baixa. O valor de mercado da razão dívida/PIB é a razão dividida por $(1+r)$.

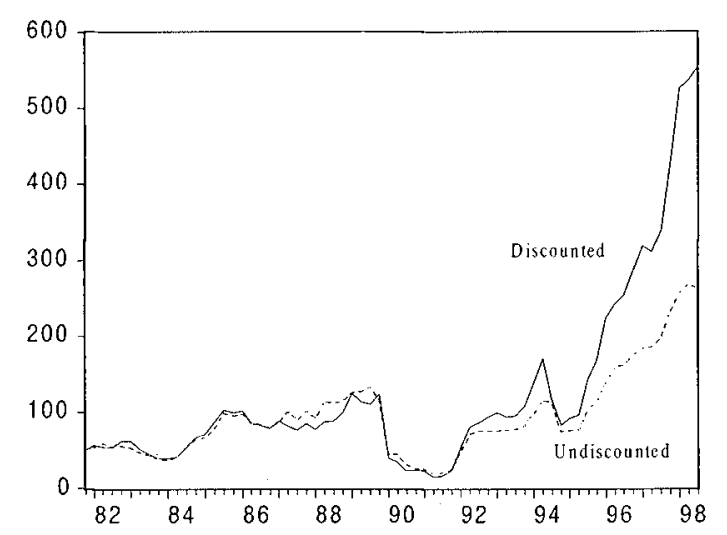

Bilions of 1997 Reais.

Figura I: The Market Value of Federal Domestic Debt 
A figura 1 mostra os valores descontados e não descontados da dívida mobiliária federal em bilhões de reais de 1997, para o período de 1981:IV a 1998:III. O valor de mercado é o valor de face da divida, multiplicado por por $1 /(1+r)$, onde $r$ é a taxa real de juros; o valor descontado da dívida é o seu valor de mercado, multiplicado pelo fator de desconto Qt. O valor de Qt é normalizado para a unidade $(Q t=1)$ no início da amostra.

Embora a razão dívida/PIB tenha crescido, o gráfico demonstra que o valor de mercado da dívida do governo no último trimestre de 1994 é aproximadamente o mesmo que em $1981(Q t=1.026)$.

Tanto a dívida descontada quanto a não descontada aumentaram regularmente durante a primeira metade da amostra, e caíram no início dos anos 90, quando da intervenção governamental no mercado de títulos. A partir 1992, porém, as duas séries reassumem seu nível prévio, indicando que a intervenção não representou uma alteração no padrão da divida governamental. Ambos os valores da dívida assumem uma forte tendência de crescimento. Ao fim da mostra, o valor não descontado da dívida mais do que dobrou em relação ao valor original de 1981; uma política de juros consistentemente positivos implementada pelo governo desde o segundo trimestre de 1994 resultou num maior crescimento do valor descontado da dívida. O comportamento observado das duas séries parece indicar não obediência a uma restrição orçamentária intertemporalmente balanceada. Testes formais de sustentabilidade são apresentados na próxima seção.

\subsection{Testes de raiz unitória}

Seguindo a apresentação teórica exposta na seção 2, a série para a dívida mobiliária descontada foi ajustada para média zero.

O primeiro passo para a implementação do teste de raiz unitária é selecionar o número de defasagens apropriado ao modelo auto-regressivo proposto.

Embora os dados consistam de observações trimestrais, o correlograma da dívida descontada (não reportado) não parece indicar componentes sazonais na série. É importante, no entanto, entreter a possibilidade de um número de defasagens não menor que quatro trimestres no teste de raiz unitária, e conferir seu nível de significância.

A equação $\Delta b_{t}=\gamma b_{t-1}+\sum_{i=2}^{12} \beta_{i} \Delta b_{t-i+1}+\varepsilon_{t}$ é estimada e a significância dos 
coeficientes das defasagens temporais é avaliada, iniciando-se com as defasagens de número 12, ou seja, 3 anos de observações.

As estatísticas $t$ para a décima segunda e oitava defasagens, importantes candidatas a componentes sazonais, indicaram que esses intervalos temporais não são significativamente diferentes de zero $(0,178$ e 0,116, respectivamente). A quarta defasagem parece ser o primeiro intervalo temporal importante, com a estatística $t$ de 1,245 . Os resíduos da regressão foram plotados e suas funções de autocorrelação examinadas (não reportado). Não há indicações de correlação serial, e um modelo com 4 defasagens parece ser apropriado para os testes de raiz unitária.

Dado que o processo gerador da dívida descontada não é conhecido, o segundo passo é determinar a equação de regressão. Começa-se com o modelo menos restritivo, que inclui uma constante e um termo de tendência. Os resultados são mostrados na Tabela 2. Os valores críticos reportados para os testes Dickey-Fuller Aumentado e Phillips-Perron baseiam-se na superfície de resposta estimada por MacKinnon (1991), a qual permite o cálculo de valores críticos para qualquer tamanho amostral.

Os resultados indicam que a hipótese nula de raiz unitária para a divida descontada não pode ser rejeitada num intervalo de confiança de $5 \%(\mathrm{ADF}$ de -1,26). O teste Dickey-Fuller Aumentado é sensivel à equação de regressão usada no teste de raiz unitária, podendo não rejeitar a hipótese nula devido à má especificação da parte determinística da regressão. Dado que a hipótese nula não foi rejeitada, é necessário testar a significância do termo de tendência sob a hipótese nula de existência de raiz unitária. A estatística $t$ para o coeficiente de tendência da divida descontada é 1,65, o que comparado ao valor crítico de Dickey-Fuller de 2,79 , indica que o termo de tendência não é significativamente diferente de zero no intervalo de confiança de $5 \%$, e que o teste de raiz unitária deve ser conduzido sem o termo de tendência.

A média da série é zero por construção e, portanto, espera-se que a constante do modelo estimado não seja estatisticamente significante. Mesmo assim, a fim de dar seqüência ao procedimento usual indicado para o teste de raiz unitária, o modelo é reestimado com um termo constante. Como esperado, esse termo é estatisticamente insignificante (valor de $t$ de $0,792)$. A estatística $\operatorname{ADF}(-0,598)$ mais uma vez não rejeita a hipótese de nulidade de raiz unitária.

Dados os resultados apresentados, a estacionaridade da divida descontada (ajustada pela média) deve ser testada através de um modelo em termo de tendência ou constante. Esse modelo, como esperado, é também selecionado pelo critério de Schwarz. 
Tabela 2: Testes de Raiz Unitária

\begin{tabular}{|c|c|c|c|}
\hline \multicolumn{4}{|c|}{$\Delta B_{t}=\alpha_{1}+\gamma B_{t-1}+\alpha_{2} t+\sum_{i=2}^{4} \delta_{i} B_{t-i+1}+\varepsilon_{t}$} \\
\hline & (1) & (2) & (3) \\
\hline \multirow[t]{2}{*}{$B_{t-1}$} & -0.093 & -0.040 & -0.051 \\
\hline & $(0074)$ & $(0.067)$ & $(0065)$ \\
\hline \multirow[t]{2}{*}{$\Delta B_{t-1}$} & 0.062 & 0.058 & 0.078 \\
\hline & $\left(\begin{array}{lll}0 & 137\end{array}\right)$ & $(0.139)$ & $\left(\begin{array}{l}0 \\
0\end{array}\right.$ \\
\hline \multirow[t]{2}{*}{$\Delta B_{t-2}$} & 0.208 & 0.204 & 0.225 \\
\hline & $\left(\begin{array}{lll}0 & 139\end{array}\right)$ & $(0.141)$ & $(0.138)$ \\
\hline \multirow[t]{2}{*}{$\Delta B_{t-3}$} & 0.116 & 0.099 & 0.119 \\
\hline & $(0.1+1)$ & $(0.143)$ & $(0.140)$ \\
\hline \multirow[t]{2}{*}{$\Delta B_{t-4}$} & -0.165 & -0.187 & -0.172 \\
\hline & $(0.141)$ & $(0.142)$ & $(0.141)$ \\
\hline \multirow[t]{2}{*}{$\alpha$} & -0.927 & 0.262 & \\
\hline & $(0792)$ & $(0.033)$ & \\
\hline \multirow[t]{2}{*}{$\mathrm{T}$} & 0.033 & & \\
\hline & $(0.020)$ & & \\
\hline ADF Stat & -1.263 & -0.597 & -0.786 \\
\hline $\operatorname{ADF}(5 \%)$ & -3.481 & -2.908 & -1.946 \\
\hline PP Stat & & & -0.695 \\
\hline $\mathrm{PP}(5 \%)$ & & & -1.945 \\
\hline
\end{tabular}

Desvio padrão em parênteses.

O teste Dickey-Fuller Aumentado falhou em rejeitar a hipótese nula de raiz unitária na série da dívida descontada, ajustada pela média. A estatística ADF calculada (-0,786) é muito acima do valor crítico reportado de $-1,946$ no intervalo de confiança de $5 \%$. O teste de PhillipsPerron corrige a estatistica para a correlação serial e possíveis termos heterocedásticos. A estatística calculada de $-0,695$ também indica a presença de raiz unitária na série. Os resultados indicam, conseqüentemente, que a dívida descontada não é estacionária e que, por conseqüência, a dívida mobiliária brasileira realmente assumiu um nível insustentável depois de 1981. 


\subsection{Um teste de estacionaridade}

Testes tradicionais de raiz unitária, como os desenvolvidos por Dickey-Fuller e Phillips-Perron são desenhados para rejeitar a hipótese de nula a não ser que haja forte evidência contra ela. A hipótese nula representa, em geral, a existência de raiz unitária na série sendo testada. Como resultado, esses testes falham em rejeitar a nulidade de raiz unitária (não estacionaridade) em diversas séries econômicas. Kwiatkowski, Phillips, Schmidt e Shin (1992) desenvolveram um procedimento que permite testar diretamente a hipótese de estacionaridade (ausência de raiz unitária), o teste conhecido como KPSS.

Esse procedimento foi usado para testar a sustentabilidade da dívida mobiliária brasileira de 1966 a 1996 e a hipótese nula de estacionaridade não pôde ser rejeitada (Luporini, 1998). A amostra foi então dividida em duas subamostras. Os testes tradicionais de raiz unitária indicaram que a dívida mobiliária federal assumiu um padrão insustentável após 1981. Devido à utilização de dados anuais, o estudo anterior não possibilitou a aplicação do procedimento KPSS à subamostra devido aos poucos graus de liberdade para implementá-lo. Como conseqüência, não foi possivel descartar a possibilidade de que a não estacionaridade da dívida brasileira após 1981 tenha sido, na verdade, resultado da especificação da hipótese nula pelos testes tradicionais. A amostra utilizada aqui permite graus de liberdade suficientes para que uma investigação adicional a respeito da não-estacionaridade da dívida brasileira após 1981 seja conduzida utilizando o teste de KPSS.

\section{O Procedimento KPSS}

O teste de estacionaridade (nível) é baseado na estatística $\hat{\eta}_{\mu}=T^{-2} \frac{\sum_{t=1}^{T} S_{t}^{2}}{s^{2}(l)}, \quad$ onde $\quad S_{t}=\sum_{i=1}^{t} e_{i}, \quad \mathrm{t}=1,2, \ldots, \mathrm{T} \quad$ é $\quad \mathrm{o}$ processo parcial de resíduos da regressão $y_{t}=\bar{y}+e_{t}$; $s^{2}(l)=T^{-1} \sum_{t=1}^{T} e_{t}^{2}+2 T^{-1} \sum_{s=1}^{l} w(s, l) \sum_{t=s+1}^{T} e_{t} e_{t-s}$ é um estimador consistente da variância do erro; $\mathrm{w}(s, l)=1-\mathrm{s} /(l+1)$ é uma função de ponderação que garante a não negatividade de $s^{2}(l)$; e $l$ é o parâmetro de defasagem. 
Um parâmetro $(l=0)$ implica não correção para autocorrelação.

Os resultados sāo apresentados na Tabela 3. Quanto maior o parâmetro de defasagem $l$, maior deve ser o tamanho da amostra para que os resultados assintóticos sejam relevantes e, infelizmente, os valores do teste estatístico diminuem na medida em que o parâmetro de defasagem cresce. Um parâmetro de defasagem adequado pode ser obtido utilizando o número inteiro do valor $(T / 100)^{025}$, onde T é o número de observações. Dessa forma, a amostra de 68 observações fornece um parâmetro de defasagem de 1 . Os valores críticos aos níveis de 5 e 10\% são 0,463 e 0,347, respectivamente. Nesse caso, a hipótese nula de estacionaridade é rejeitada no nível de $5 \%$. Para o intervalo truncado de 1 , o teste KPSS claramente indica que a dívida mobiliária federal assumiu um padrão insustentável após 1981, um resultado consistente com o obtido previamente.

Tabela 3: Teste de Estacionaridade

\begin{tabular}{lc}
\hline & $\hat{\eta}_{\mu}=T^{-2} \frac{\sum_{t=1}^{T} S_{t}^{2}}{S^{2}(1)}$ \\
\hline$l=0$ & 2.081 \\
$I=1$ & 1.111 \\
$I=2$ & 0.465 \\
$I=3$ & 0.336 \\
$I=4$ & 0.364 \\
$\eta_{\mu}$ critical values & 0.144 \\
\hline
\end{tabular}

Valores críticos, nível de estacionaridade, KPSS (1992), p. 156.

\section{Observações finais}

Esse artigo analisou a sustentabilidade da dívida mobiliária federal no Brasil e foi motivado por resultados obtidos previamente (Luporini, 1998) em que a dívida brasileira havia assumido um padrão insustentável após 1981. O diagnóstico do estudo supracitado poderia ter sido resultado do pequeno número amostral utilizado nos testes 
econométricos. A nova amostra obtida permitiu investigações adicionais da sustentabilidade da dívida mobiliária federal após 1981.

Uma dívida pode ser considerada sustentável quando o governo respeita uma restrição orçamentária intertemporalmente balanceada. Econometricamente, a condição para sustentabilidade é a estacionária para a série de dívida apropriadamente descontada. O nível da dívida mobiliária federal brasileira foi analisado tanto pelos testes de raiz unitária tradicionais quanto pelo procedimento desenvolvido por Kwiatkowski, et al.(1992). Os procedimentos Dickey-Fuler Aumentado e o Phillips-Perron testam a presença de raiz unitária com base na hipótese nula de não-estacionaridade, enquanto o teste Kwiatkowski baseia-se na hipótese nula de estacionaridade. Os resultados de ambos os testes, aplicados a uma nova amostra, indicaram que a divida mobiliária federal assumiu um padrão insustentável após 1981, confirmando o diagnóstico previamente obtido. O governo federal parece de fato estar acumulando dívidas excessivas que podem vir a ameaçar sua capacidade de financiamento.

Ainda uma outra possibilidade para investigações adicionais sobre a natureza da acumulação da dívida mobiliária federal consiste em verificar até que ponto a intervenção governamental no mercado overnight em 1990 constitui ou não uma quebra estrutural na série da dívida que poderia explicar os resultados obtidos aqui. 


\section{Anexo}

Tabela 1: Fator de desconto e Valores Trimestrais do PIB

\begin{tabular}{|c|c|c|}
\hline obs & Qt. & PIB (Milhões de Reais de 1997) \\
\hline $1981: 4$ & 1.000000 & 139841.5 \\
\hline 1982:1 & 0.983000 & 139964.4 \\
\hline 1982:2 & 0.862000 & 155545.0 \\
\hline $1982: 3$ & 0.919000 & 153224.8 \\
\hline $1982: 4$ & 1.042000 & 144512.6 \\
\hline 1983:1 & 1.082000 & 135600.6 \\
\hline $1983: 2$ & 1.008000 & 149322.0 \\
\hline $1983: 3$ & 0.945000 & 147923.7 \\
\hline $1983: 4$ & 0.971000 & 143083.6 \\
\hline 1984:1 & 0.993000 & 141516.3 \\
\hline $1984: 2$ & 0.913000 & 156559.1 \\
\hline $1984: 3$ & 0.938000 & 155913.8 \\
\hline $1984: 4$ & 0.948000 & 153701.2 \\
\hline $1985: 1$ & 0.989000 & 150996.8 \\
\hline $1985: 2$ & 1.032000 & 165133.1 \\
\hline $1985: 3$ & 0.976000 & 170080.8 \\
\hline $1985: 4$ & 0.963000 & 168697.9 \\
\hline $1986: 1$ & 0.962000 & 162060.0 \\
\hline 1986:2 & 0.904000 & 177686.7 \\
\hline 1986:3 & 0.913000 & 183848.3 \\
\hline $1986: 4$ & 0.914000 & 180775.2 \\
\hline 1987:1 & 0.955000 & 174582.9 \\
\hline $1987: 2$ & 0.756000 & 189825.5 \\
\hline $1987: 3$ & 0.798000 & 184877.8 \\
\hline $1987: 4$ & 0.783000 & 180713.7 \\
\hline 1988:1 & 0.788000 & 174690.4 \\
\hline $1988: 2$ & 0.713000 & 189087.9 \\
\hline $1988: 3$ & 0.732000 & 189180.1 \\
\hline $1988: 4$ & 0.803000 & 176703.3 \\
\hline 1989:1 & 0.921000 & 169804.2 \\
\hline 1989:2 & 0.828000 & 195602.9 \\
\hline 1989:3 & 0.777000 & 199137.0 \\
\hline 1989:4 & 0.969000 & 188657.7 \\
\hline $1990: 1$ & 0.828000 & 174506.0 \\
\hline 1990:2 & 0.735000 & 177640.6 \\
\hline 1990:3 & 0.696000 & 191607.9 \\
\hline 1990:4 & 0.836000 & 177333.3 \\
\hline 1991:1 & 0.829000 & 161940.7 \\
\hline 1991:2 & 0.755000 & 183136.5 \\
\hline $1991: 3$ & 0.749000 & 190089.7 \\
\hline 1991:4 & 0.888000 & 179828.0 \\
\hline 1992:1 & 1.034000 & 168929.3 \\
\hline 1992:2 & 1.044000 & 179969.5 \\
\hline $1992: 3$ & 1.066000 & 183490.3 \\
\hline $1992: 4$ & 1.161000 & 178748.7 \\
\hline 1993:1 & 1.218000 & 174661.7 \\
\hline
\end{tabular}




\begin{tabular}{lll}
$1993: 2$ & 1.136000 & 189417.4 \\
$1993: 3$ & 1.132000 & 193132.8 \\
$1993: 4$ & 1.222000 & 188904.3 \\
$1994: 1$ & 1.309000 & 182924.2 \\
$1994: 2$ & 1.376000 & 195273.6 \\
$1994: 3$ & 0.970000 & 204845.4 \\
$1994: 4$ & 1.026000 & 206720.8 \\
$1995: 1$ & 1.118000 & 201996.8 \\
$1995: 2$ & 1.167000 & 207782.3 \\
$1995: 3$ & 1.276000 & 206968.5 \\
$1995: 4$ & 1.370000 & 206349.2 \\
$1996: 1$ & 1.478000 & 199148.3 \\
$1996: 2$ & 1.415000 & 212453.2 \\
$1996: 3$ & 1.443000 & 218061.8 \\
$1996: 4$ & 1.516000 & 216150.9 \\
$1997: 1$ & 1.611000 & 206650.0 \\
$1997: 2$ & 1.552000 & 220998.7 \\
$1997: 3$ & 1.598000 & 223688.0 \\
$1997: 4$ & 1.715000 & 220503.3 \\
$1998: 1$ & 1.888000 & 211360.4 \\
$1998: 2$ & 1.851000 & 225216.0 \\
$1998: 3$ & 1.963000 & 225992.1 \\
\hline
\end{tabular}

Fonte: Elaboração própria.

\section{Referências bibliográficas}

AHMED S. 3 ROGERS J. "Government budget deficits and trade deficits: are present value constraints satisfied in long-term data?". Journal of Monetary Economics 36:351-374, 1995.

BANCO CENTRAL DO BRASIL, Boletim do Banco Central do Brasil, Departamento Econômico.

. Relatório Anual, Departamento Econômico.

BLANCHARD, O. 8 FISCHER S. Lectures on Macroeconomics. Cambridge: The MIT Press, 1989.

BOHN, $\mathrm{H}$. "The sustainability of budget deficits with lump-sum and with income-based taxation". Journal of Money, Credit, and Banking 23(3):581 604, 1991.

. "The sustainability of budget deficits in a stochastic economy". Journal of Money, Credit, and Banking 27(1)(February):257-71, 1995. CARVALHO, C. "Liquidez e choques inflacionários". In: BELLUZZO, L. \& BATISTA Jr., P. (eds.) A luta pela moeda nacional: ensaios em homenagem a Dilson Funaro. São Paulo, Paz e Terra Editora, 1992. 
DICKEY, D. \& FULLER, W. "Distribution of the estimators for autoregressive time series with a unit root". Journal of the American Statistical Association 74:427-31, 1979.

. "Likelihood ratio statistics for autoregressive time series with a unit root". Econometrica 49:1057-72, 1981.

HAKKIO, C. \& RUSH, M. "Is the budget deficit 'too large'?" Economic Inquiry 39 (July): 429-445, 1991.

HAMILTON, J. \& FLAVIN, M. "On the limitations of government borrowing: a framework for empirical testing". The American Economic Review 76(4): 809-19, 1986.

INSTITUO BRASILEIRO DE GEOGRAFIA E ESTATÍSTICA. Anuário Estatístico do Brasil.

ISLLER, J. V. E LIMA, L.R. "Public debt sustainability and endogenous seignorage in Brazil: time-series evidence from 194792". Ensaios Econômicos da EPGE, 306, 1997.

KREMMERS, J. "U.S. federal indebtedness and the conduct of fiscal policy". Journal of Monetary Economics 23:219-38, 1989.

KWIATKOWSKI, D., PHILLIPS, P., SCHMIDT, P., \& SHIN, Y. “Testing the null hypothesis of stationarity against the alternative of a unit root". Journal of Econometrics 54:159-78, 1992.

LUPORINI, V. Central bank independence and the federal domestic debt: a study of the Brazilian case, 1966-1996. Ph.D. Thesis. The City University of New York, 1998.

MADDALA, G. and I. KIM. Unit roots, cointegration, and structural change. Cambridget, Cambridge University Press, 1998.

MC CALLUM, B. "Are bond-financed deficits inflationary? A Ricardian analysis". Journal of Political Economy 92(1):123-35, 1984.

PASTORE, A. "Déficit público, a sustentabilidade das dívidas interna e externa, seignoriagem e inflação: uma análise do regime monetário brasileiro". Revista de Econometria, 14(2), 1995.

PHILLIPS, P. e PIERRON, P. "Testing for a unit root in time series regression". Biometrika 75:335-46, 1988.

TANNER E. 8 LIU, P.. "Is the budget deficit 'too large'? Some further evidence”. Economic Inquiry 32 (July):511-518, 1994. 
TREHAN, B. \& WALSH, C. “Testing intertemporal budget constraints: theory and applications to U.S. federal budget and current account deficits". Journal of Money, Credit, and Banking 23(2):206-23, 1991.

UCTUM, M. 8 WICKENS, M. "Debt and deficit ceilings, and sustainability of fiscal policies: an intertemporal analysis". Mimeographed. New York, Brooklyn College and the Federal Reserve of New York, 1996.

WILCOX, D. "The sustainability of government deficits: implications of the present-value borrowing constraint". Journal of Money, Credit, and Banking 21(3):291-306, 1989. 